\title{
Pensamento Computacional na Formação de Professores de Matemática
}

\author{
Kátia Coelho da Rocha - PPGIE/UFRGS - katiacoelhorocha@ gmail.com - \\ https://orcid.org/0000-0002-7433-4471 \\ Marcus Vinicius de Azevedo Basso - PPGIE/UFRGS - mbasso@ufrgs.br - \\ https://orcid.org/0000-0002-2312-9056
}

\begin{abstract}
Resumo
A definição de Pensamento Computacional é um conceito em construção. Diversos autores definem o conceito sob diferentes perspectivas, o que resulta em práticas mais voltadas à programação, à resolução de problemas, ou centradas em outros conceitos da Ciência da Computação. A partir dessa variedade de definições e práticas desenvolvemos uma pesquisa de doutorado, em andamento, e que visa identificar como esses conceitos da computação podem contribuir para a aprendizagem de conceitos matemáticos, sob a ótica da teoria da abstração reflexionante de Piaget. Neste artigo é apresentada uma de um conjunto de atividades que serão propostas em uma formação de professores Matemática. Dois professores realizaram essa atividade e nesse artigo apresentamos os resultados analisados à luz da teoria de Piaget. Identificamos que o Pensamento Computacional e seus processos podem servir como objetos-de-pensar-com, de acordo com os princípios do Construcionismo de Papert, nos processos de abstração reflexionante do sujeito.
\end{abstract}

Palavras-chave: pensamento computacional, objetos-de-pensar-com, pensamento por procedimentos, abstração reflexionante, formação de professores de Matemática

\section{Computational Thinking in Mathematics Teacher Education}

\begin{abstract}
The definition of Computational Thinking is an under construction concept. Several authors define the concept from different perspectives, which results in practices more focused on programming, problem solving, or focused on other concepts of Computer Science. Based on this variety of definitions and practices, we have developed an ongoing doctoral research, which aims to identify how these computing concepts can contribute to the learning of mathematical concepts, from the perspective of Piaget's reflective abstraction theory. This article presents an activity of a set of activities that will be proposed in a Mathematics teacher education. Two teachers carry out this activity and in this article we present the results analyzed in the light of Piaget's theory. We identified that Computational Thinking and its processes can serve as objects-to-think-with, according to the principles of Papert's Constructionism, in the processes of reflective abstraction of the subject.
\end{abstract}

Key-words: computational thinking, objects-to-think-with, procedural thinking, reflecting abstraction, Mathematics teacher education

\section{INTRODUÇÃO}

A Computação está cada vez mais sendo vista como uma ciência além dos computadores (máquinas), tornando-se "um método essencial para se fazer ciência" (Denning, p.3, 2009). Desta forma, Denning (2009) argumenta a necessidade da computação para o desenvolvimento de outras áreas, como por exemplo, a Bioinformática em que os modelos computacionais permitiram o mapeamento completo do genoma humano. Essa evolução da computação a afasta puramente dos computadores e a torna 
uma ciência que tem como foco o estudo do processamento de informações computacionais, sejam elas naturais ou artificiais (Dening, 2009, 2017; Li et al, 2020).

Ao mesmo tempo que a Computação foi conquistando seu espaço como ciência, pesquisadores da área também observavam o desenvolvimento do pensamento que era influenciado por práticas computacionais e que aprender sobre seus processos computacionais poderia influenciar a vida e a profissão das pessoas. Essas observações podem ser consideradas a origem do Pensamento Computacional.

Desde os anos 60 já se falava em Pensamento Computacional como uma referência para descrever os processos de pensamento dos cientistas da computação que se diferenciam de outros, muitas vezes, esse termo era usado como sinônimo de "pensamento algoritmo". Na década de 80 Seymour Papert usou o termo Pensamento Computacional em seu livro Mindstorms (em português: Logo: Computadores e Educação) ao tratar das habilidades mentais que são desenvolvidas por atividades de programação em LOGO por crianças. Papert, em seu artigo An Explorationin the Space of Mathematics Educations de 1996, reforça o poder do Pensamento Computacional para "forjar ideias", levando o sujeito a resolver problemas que surgem nos micromundos, ampliando e enriquecendo as representações do conhecimento.

O termo ganha destaque em 2006, quando Jeannette Wing, pesquisadora e professora da área da computação, utiliza o termo Pensamento Computacional em um artigo em que argumenta a importância de pensar como um cientista da computação definindo como sendo "uma distinta forma de pensamentos com conceitos básicos da Ciência da Computação para resolver problemas, desenvolver sistemas e para entender o comportamento humano, habilidade fundamental para todos" (Wing, 2006, p.1)

A partir da publicação do artigo de Wing(2006) diversas pesquisas e definições de Pensamento Computacional surgiram. Entre as definições pesquisadas destacamos as propostas por: Wing (2006, 2014), Grover e Pea (2013), Shute, Sun e Asbell-Clarke (2017), Aho (2012), Hu (2011), Brennan e Resnick (2012), Brackmann (2017), Yasar (2018), Li et al (2020) e observamos que elas apresentam características diversas que indicam que o Pensamento Computacional pode ser: programação que gera outras habilidades e reflexões; uma metodologia para a resolução de problemas; a fusão de outros pensamentos; uma capacidade para usar conceitos computacionais; um gerador de processos cognitivos.

No geral, as pesquisas mostram semelhanças entre si, como o reconhecimento de que a programação tem laços estreitos com o Pensamento Computacional, mesmo que ele não seja sinônimo de programação. Wing admite que pensar como cientista da computação vai além de programar um computador, mas pensar em vários níveis de abstração (Wing, 2006).

Denning (2017) e outros autores (Li et al, 2020; Grover; Pea, 2013) afirmam que a variedade de definições, a imprecisão sobre o que é Pensamento Computacional, como desenvolvê-lo e a falta de uma análise mais detalhada sobre possíveis efeitos do Pensamento Computacional levam a diversos tipos de práticas que fazem uso desse termo como referência. Muitas dessas práticas estão engajadas em ensinar ou inserir computação no dia a dia, trazendo o ato de programar como chave do processo ou ainda propondo escritas de procedimentos, sem, no entanto, analisar o desenvolvimento cognitivo que essas práticas podem proporcionar. Diante disso, esta pesquisa tem como objetivo usar o conceito dos objetos-de-pensar-com de Papert (1985) e acrescentar ao conceito de Pensamento Computacional a perspectiva da abstração reflexionante de Piaget. Assim, consideramos que Pensamento Computacional são os processos de 
pensamento que utilizam elementos computacionais como objetos-de-pensar-com para contribuir nos processos de abstração reflexionante do sujeito.

O sentido atribuído ao Pensamento Computacional nesta pesquisa não está diretamente relacionado com o ensino de conceitos computacionais, mas em usar a computação e seus processos como um suporte à reflexão para a construção de níveis mais elevados de pensamento. Desta forma, a programação não é o foco principal, e concordando com as ideias de Papert (1985), di Sessa (2018), Li et al (2020) acreditamos na computação com um propósito maior do que ela mesma, expandindo as capacidades e engajando o sujeito em um processo ativo na sociedade.

\section{OBJETOS-DE-PENSAR-COM E ABSTRAÇÕES REFLEXIONANTES}

Papert (1985) faz uma reflexão sobre o processo de inserção da computação no ambiente escolar e mostra suas inquietações sobre um ensino que, naquele momento, estava propondo um uso mecânico do computador. Ele vislumbra um novo ambiente que pode ser proporcionado com o uso dos computadores, um espaço em que ele seja usado como um objeto-de-pensar-com, trazendo suporte para o sujeito desenvolver seu pensamento, ampliando seus processos de reflexão. Desta forma, o computador torna possível a inserção do sujeito em micromundos em que ele pode testar suas hipóteses, refletir sobre os resultados obtidos, adaptar ideias e criar relações durante a resolução de um problema, fazendo uma reflexão sobre seu próprio pensamento.

De acordo com (Rocha; Basso e Notare, 2020), os objetos-de-pensar-com podem ser considerados instrumentos de pensamento em que o sujeito pode se apropriar para auxiliá-lo em seu processo de pensar sobre diferentes conceitos. Ao criar um programa no Scratch, por exemplo, o ator pode ser utilizado como um objeto-de-pensar-com, que faz com que o sujeito utilize a linguagem computacional para se comunicar ao mesmo tempo em que observa, analisa e reflete sobre as ações do programa e os conceitos implícitos na atividade. Assim, esse tipo de pensamento traz um processo de descrição analítico, que auxilia nos processos de abstrações reflexionantes, levando a abstrações refletidas.

O termo abstração é comumente apresentado como o elemento essencial no desenvolvimento do Pensamento Computacional. Wing (2014) destaca a abstração como um mecanismo que auxilia na captura das propriedades comuns nos conjuntos de objetos e reconhece sua importância para esse pensamento. (Rocha; Basso e Notare, 2020) abordam esse tema principalmente sob o enfoque piagetiano e identificam possíveis aproximações entre esses processos de abstração. Os autores afirmam que, para a computação, a abstração está muito relacionada ao lado operacional usado durante o processo de criar uma solução para um problema, porém as possibilidades para o desenvolvimento cognitivo do sujeito não são exploradas em publicações e pesquisas. Já Papert (1985), que tem como pano de fundo a teoria de Piaget, ao tratar do pensamento por procedimentos e todo o universo dos micromundos criados pelo ambiente computacional, está interessado em como isso pode afetar o modo de pensar e aprender dos sujeitos.

De acordo com Becker (2012), abstrair significa retirar, extrair algo de alguma coisa. Portanto, abstrair relaciona-se com características, sejam elas visíveis ou não, como por exemplo reconhecer que um objeto possui características comuns a outros objetos, fazer relações a partir dele. Para Piaget (1977), o processo de abstração torna-se possível a partir dos esquemas que o sujeito possui e que lhe permitem retirar informações do objeto em análise.

As abstrações que se apoiam sobre objetos físicos ou sobre as ações do sujeito nos aspectos materiais são denominadas por Piaget de abstrações empíricas. As abstrações 
que são apoiadas em características não observáveis e envolvem atividades cognitivas dos sujeitos são chamadas de abstrações reflexioantes (Piaget, [1977],1995). O processo de abstração reflexionante envolve dois sentidos que se complementam: o reflexionamento que é a transposição, para um patamar superior, o que foi retirado de um inferior; e a reflexão: que envolve reconstrução e reorganização sobre o patamar superior o que foi transferido de um inferior (Piaget, [1977],1995; Becker, 2012). No final do processo de abstração reflexionante pode ocorrer uma tomada de consciência e essa abstração passa a ser chamada de abstração refletida.

A abstração reflexionante também pode se apoiar em um objeto, neste caso a propriedade abstraída não é a do objeto, mas ele é modificado pelo sujeito através de suas ações e enriquecido de propriedades que são retiradas de suas coordenações. Essa abstração é denominada por Piaget de abstração reflexionante pseudo-empírica.

Identificamos que os objetos-de-pensar-com propostos por Papert são um suporte aos processos de abstração reflexionante, permitindo que o sujeito pense sobre seu próprio pensamento e amplie seus mecanismos de reflexão. Assim, consideramos que o os processos de pensamento que utilizam elementos computacionais podem se tornar objetos-de-pensar-com contribuindo com os processos de abstração reflexionante.

\section{MATERIAIS E MÉTODOS}

A pesquisa de campo está em fase inicial e nesse momento foram realizados os primeiros experimentos que serão aprimorados para a segunda fase da produção de dados. Para esta fase foram realizados cinco encontros online individuais com duas professoras de Matemática. Nos encontros foram aplicadas parte das atividades que irão compor a produção final de dados da pesquisa. Neste artigo apresentaremos uma das atividades desenvolvidas, denominada de Mágica do Calendário, que será apresentada a seguir e analisada na próxima seção. O objetivo dessa atividade é identificar possíveis contribuições do uso do algoritmo, um dos elementos que compõem o Pensamento Computacional, para promover processos de abstração reflexionante em professores de matemática. Assim, pretendemos ampliar a visão e as possibilidades de uso dos elementos da Computação na aprendizagem matemática.

\subsection{Apresentação da atividade: Mágica do Calendário}

A atividade consiste em uma aplicação da Mágica do calendário, adaptada do livro Incríveis Passatempos Matemáticos de Stewart (2010). Cada participante deveria escolher um calendário de um mês e ano qualquer em que seus dias estivessem organizados em 7 colunas por mês, destacando os dias da semana. Após deveriam imaginar um quadrado $3 \times 3$ ao redor de nove datas, sem que sobrasse espaço em branco. Ao final informavam qual a menor data do quadrado e então a pesquisadora lhes informava a soma dos nove números. Abaixo, a figura 1 apresenta um modelo de calendário com o quadrado $3 \times 3$ marcado:

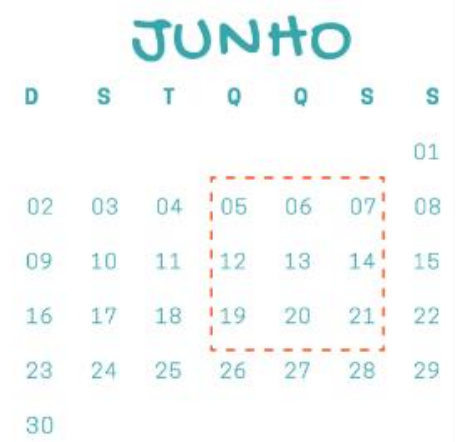

Figura 1- Exemplo do calendário com o quadrado 3x3 
Após a realização da mágica cada participante foi desafiada a escrever um algoritmo que representasse as etapas da mágica. A partir da discussão sobre como cada uma criou seu algoritmo foi apresentado um modelo de programa do Scratch que executava a mágica. Optou-se por uma atividade guiada considerando que se tratava da primeira experiência das participantes com o software. De posse desse modelo, cada participante foi convidada a transpor a mágica para o software. O modelo de código enviado a cada participante pode ser visto na figura 2 :

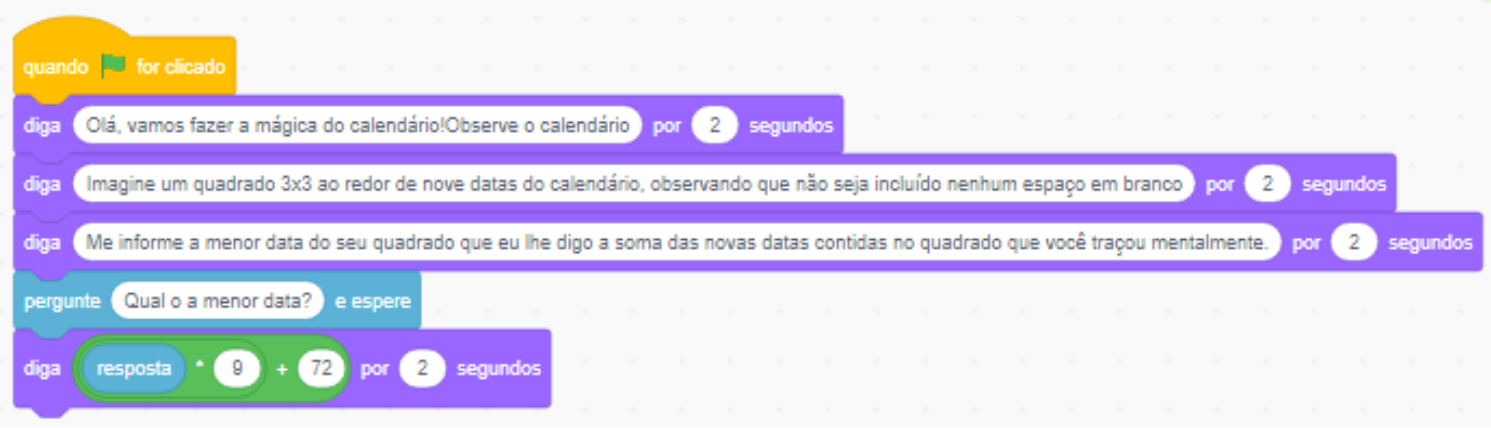

Figura 2 - Modelo de código da mágica

\section{RESULTADOS E DISCUSSÃO}

Inicialmente as duas participantes indicaram que não conheciam a mágica e ao serem desafiadas a escrever o algoritmo que representava a situação indicavam uma certa confusão em quais informações deveriam ser apresentadas. A pesquisadora afirmava que deveriam "criar um manual" para que alguém pudesse realizar a mágica, mesmo assim a dúvida delas estava em torno de quais etapas deveriam ser descritas e em como chegar à fórmula geral da soma dos dias contidos no quadrado.

O algoritmo de Katherine ${ }^{1}$ contém explicações mais detalhadas e que indicam que seu objetivo era ensinar um professor a realizar a atividade, conforme pode ser observado pela figura 3.

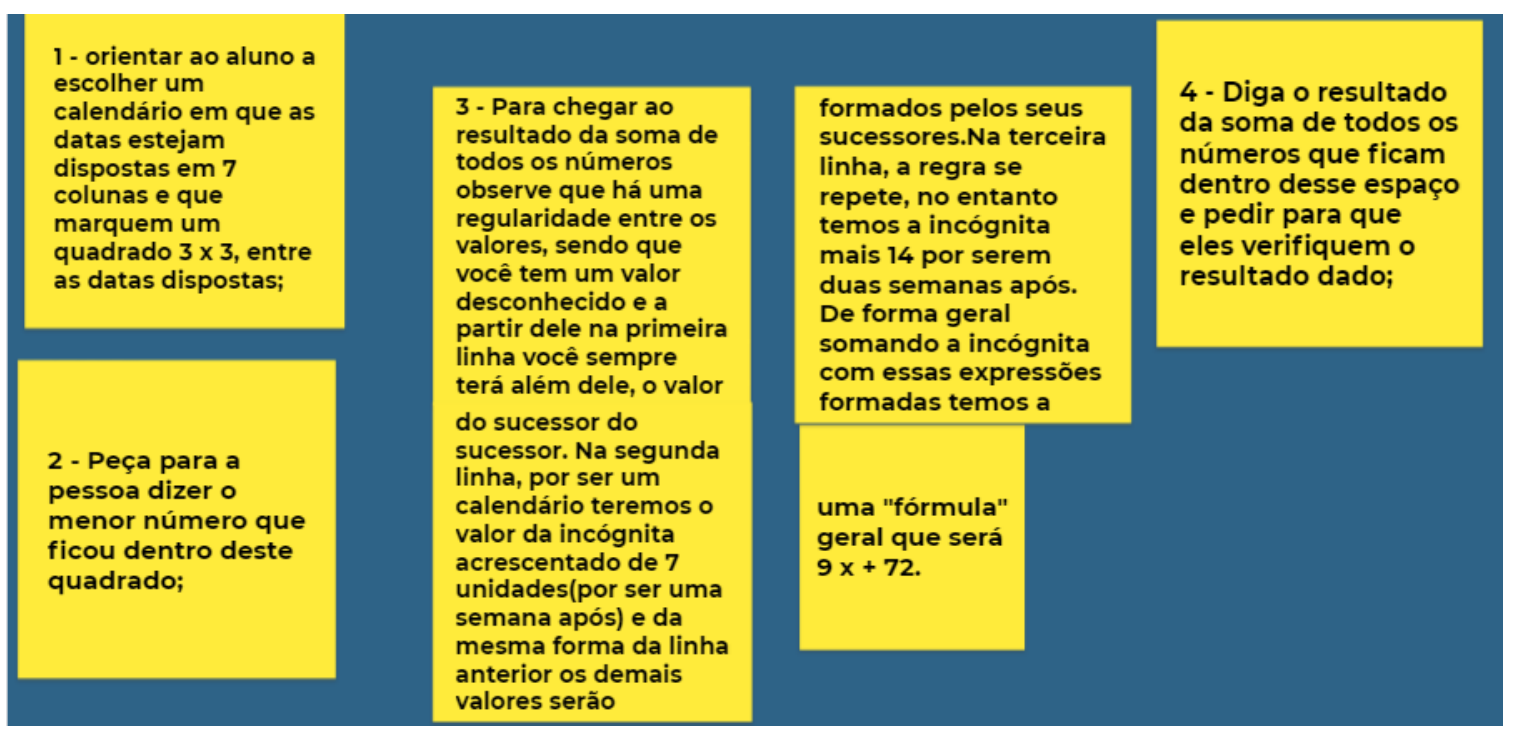

Figura 3 - Algoritmo da Mágica do Calendário - Katherine

Em seu algoritmo Katherine apresenta uma explicação completa sobre o seu próprio processo de compreensão da mágica, transpondo todas as propriedades

\footnotetext{
${ }^{1}$ A fim de manter a identidade preservada das participantes seus nomes foram substituídos por nomes de duas matemáticas que ganharam destaque na década de 60 em seu trabalho na NASA.

V. $19 \mathrm{~N}^{\mathrm{O}} 2$, Dezembro, 2021

DOI: https://doi.org/10.22456/1679-1916.121366

RENOTE
} 
identificadas ao longo da sua compreensão e escrita da fórmula geral que calcula a soma dos números que compõem o quadrado. Observamos que essa escrita lhe permitiu pensar sobre o seu próprio ato de pensar, ao mesmo tempo que demonstrava suas abstrações pseudo-empíricas sobre a atividade, como também é observado em suas falas:

Katherine: Os valores da primeira linha eu tenho como saber a partir do número dito.

Pesquisadora: É, mas como eu poderia descobrir os números da segunda linha? Como saberia quem está abaixo do 5 ?

Katherine: Por ser um calendário a gente sabe que é de 7 em 7. Então ali já consigo descobrir os números que estão abaixo. Esse que não sei é o x. Eu teria q fazer um por um: $x+1, x+2, x+3 \ldots x+16$.

Pesquisadora: E será que você consegue pensar em um jeito que facilite para fazer a mágica?

Katherine: Deixa eu me organizar melhor (passa a escrever)

Katherine: $D a ́ 9 x+72$ (Ela testa alguns valores e verifica que funciona)

As falas de Katherine indicam suas compreensões iniciais do problema e demonstram as relações que faz com seus esquemas algébricos já acomodados. Durante sua escrita a participante demonstra que, do ponto de vista da abstração, ainda há uma ausência quanto a representação algébrica final, já que a presença do 9 ainda está indefinida para ela, conforme é reforçado pela sua fala transcrita abaixo:

Katherine: $O 9$ ali deve ter alguma relação ali por ser um quadrado 3x3. Ou não?

Pesquisadora: Qual relação?

Katherine: $O 9 x$.

Pesquisadora: $O$ que tu achas que é esse 9x?

Katherine: $E$ a área do quadrado

Pesquisadora: E o que representa esse 9?

Katherine: $O 9$ seria o lado vezes o lado, 3 por3. É a área do quadrado. É todo o espaço ali.

Assim, Katherine mostra que seu processo de abstração reflexionante ainda está apoiado em uma abstração pseudo-empírica, sendo que os observáveis a levam a relações não observáveis, tentando compreender os elementos que compõem o problema.

A participante Dorothy apresentou um algoritmo de maneira mais sintética, conforme pode ser observado na figura 4 .

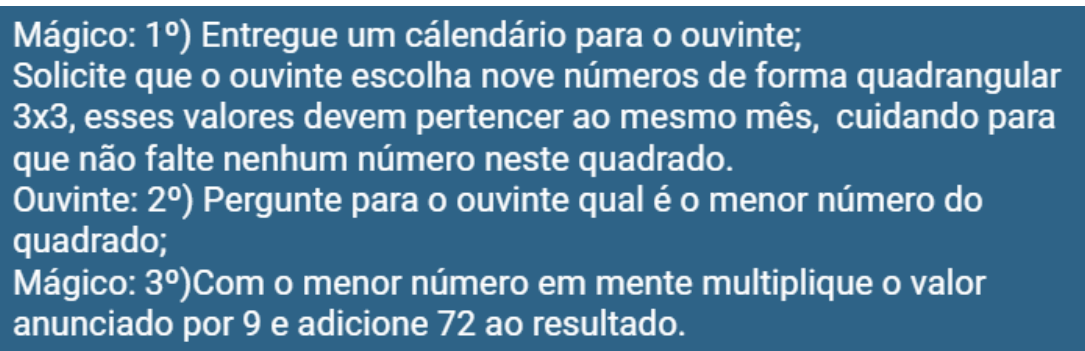

Figura 4 - Algoritmo da Mágica do Calendário - Dorothy

Ao fazer a distinção de ações do mágico e do participante, Dorothy identifica diferentes tipos de ações e que as ações do mágico têm uma relação de dependência com 
a ação do participante. A participante também menciona, durante a atividade, sua dificuldade com a escrita e em como organizar seu pensamento:

Difícil descrever, professor fala, falar é mais fácil. Não tô conseguindo montar uma ordem de exercício para isso. A minha maior dificuldade é escrever. Falar tu vai ali explica e vai dando os comandos, vai observando e a escrita tem esse..., acho que eu escrevo pouco, então eu fico no vai e volta e essa dificuldade de se fazer entender ou escrever de uma forma que que outra pessoa entenda, sei lá. Isso é uma das coisas até que a gente quer cobrar dos alunos não é só cálculo a gente tem que escrever e aí de repente a gente se pega fazendo também essas coisas, dá aquela angústia. Às vezes na aula tu tá lá explicando para o aluno, está falando, mas que não escreve, para ele é complicado será que ele vai entender só no ouvir? Parece que escrevendo a gente grava mais.

Ao compartilhar suas dificuldades, Dorothy expressa uma abstração pseudoempírica provocada pelo processo de escrita do algoritmo que se tornou um objeto-depensar-com provocando reflexões sobre a sua prática diária com os alunos. Identifica-se aqui a presença de um processo de abstração refletida no qual ela expressa a tomada de consciência.

As abstrações de Dorothy quanto às propriedades matemáticas do problema também se mostraram baseadas nos observáveis e modifica-os enriquecendo com propriedades que são fruto de coordenações anteriores (Becker, 2012), neste caso sistematizações algébricas que podem ser visualizadas na figura 5 .

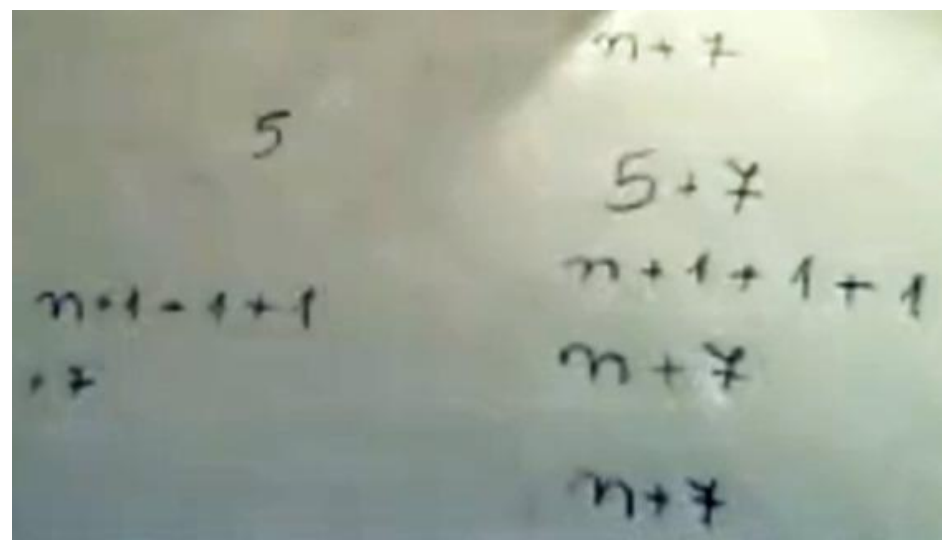

Figura 5 - Registros iniciais de Dorothy

Os registros de Dorothy mostram a organização do seu pensamento na tentativa de escrever os números que estão no calendário de uma forma geral, retirando do problema informações que provém de suas experiências anteriores. Dorothy segue sua transcrição, baseada em abstrações pseudo-empíricas, conforme expressa:

Dorothy: $O$ que está embaixo do 5 seria o $n$ mais sete e o próximo seria o $n+7+1$. Esse é o 13, mas aí tu tem $n+7+1$ para o próximo ou seja é $n+8$ ?

Pesquisadora: Tu acha que funciona?

Dorothy: Sim, 5+8 é 13! E o outro n mais nove aí na linha de baixo seria $n+14$, $n+15$ e $n+16$. Tá mas daí tu como é que tu faz essas soma? Mas tu não fica somando tudo isso né?

Pesquisadora: Não

Dorothy: Eu tenho que somar todos esses valores esse 1,2,7,8,... Vamos ver se funciona. Vou testar com o 5. Tu tinha dito que a soma quando era 5 dos números era 117 ?

Pesquisadora: Sim 
Dorothy: Ah, fechou!

Pesquisadora: E como que tu chegou?

Dorothy mostra seus registros, conforme ilustra a figura 6 .

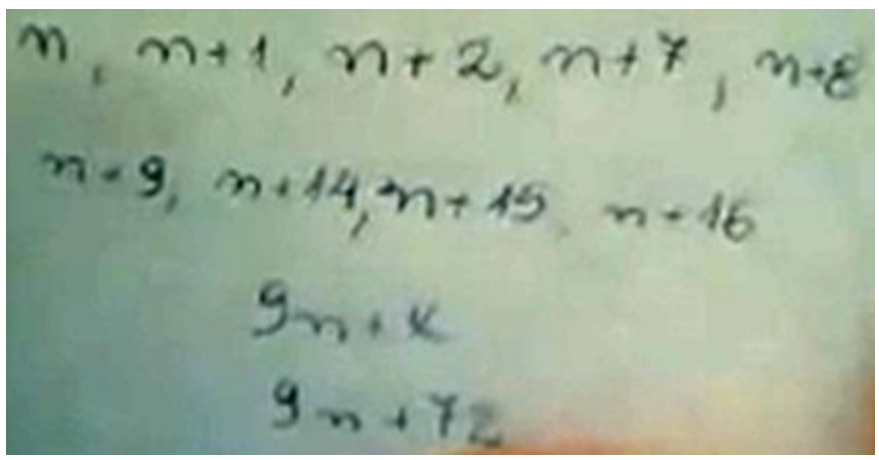

Figura 6 - Registros iniciais de Dorothy

A fala transcrita acima ilustra o momento em que Dorothy vai colocando em relação os elementos retirados de um patamar inferior com os já situados no superior evidenciando processos de abstração reflexionante.

A escrita do algoritmo que representa a mágica se mostrou uma forma de usar esse elemento da computação como um objeto-de-pensar-com levando as participantes a ativarem processos de abstração reflexionante. Observa-se que embora as participantes já dominem os conceitos matemáticos apresentados no problema, o uso da escrita algorítmica e a representação do problema como um programa lhes permitiu usar esse elemento da computação como um objeto-de-pensar-com provocando novas abstrações reflexionantes. Identificamos que em todo esse processo as participantes se apoiaram em suas atividades cognitivas anteriores fruto de abstrações reflexionantes sobre conceitos algébricos e toda a sua estrutura conceitual.

A seguir será analisada a reprodução do algoritmo no Scratch pelas participantes. Inicialmente a pesquisadora apresentou o software Scratch mostrando as ferramentas básicas, destacando os conjuntos de blocos, a área de comandos e o palco. Após essa apresentação inicial cada participante iniciou sua reprodução.

O processo de reprodução do código transcorreu de forma semelhante para as duas participantes. Realizaram toda a programação, conforme o modelo, porém, ao final indicaram um erro no programa: ele não calculava corretamente o resultado da expressão. Ao fazer alguns testes Katherine supõe que seu erro esteja no último bloco do programa, ou seja, no bloco responsável pela soma, o mesmo ocorreu com Dorothy. A figura 7 apresenta o programa de Katherine.

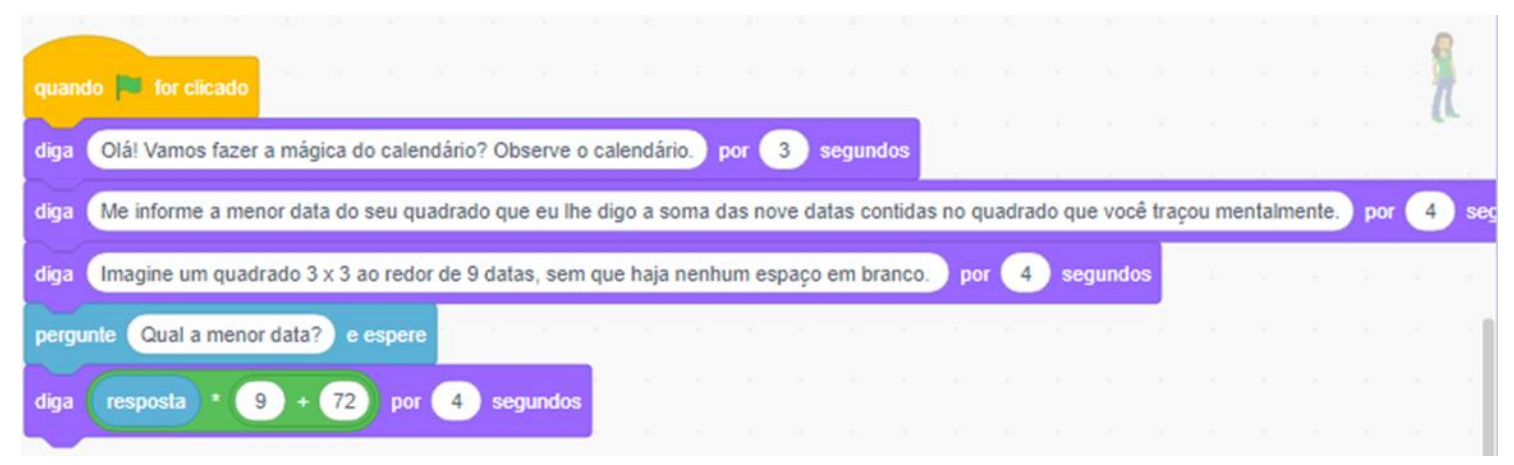

Figura 7 - Programa do calendário com bug - Katherine 
Os programas criados pelas duas participantes são muito semelhantes e possuem o mesmo bug que impede que ao final seja realizada a soma dos números do quadrado corretamente. O bug nos programas está no encaixe dos blocos, já que o bloco da soma está dentro do segundo fator da multiplicação o que implica na seguinte ordem de resolução resposta $\times(9+72)$. Ou seja, a adição será realizada primeiro e o seu resultado será multiplicado pela resposta digitada pelo usuário. Apresentamos a investigação desse erro por parte de uma das participantes:

Katherine: Eu não sei se é essa parte aqui que eu não encaixei certo.

Nesse momento Katherine desencaixa o bloco da soma conforme ilustra a figura 8 e segue sua investigação.

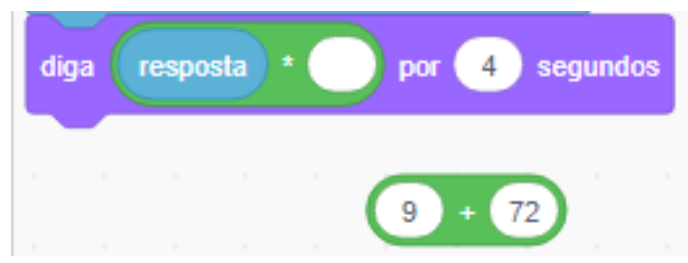

Figura 8 - Investigação de Katherine

Katherine: Não sei se aqui essa partezinha aqui eu nunca achei certo, olha aqui é daquele mesmo que tinha que colocar a resposta vezes. Eu coloco em cima o valor aqui. Eu não achei outra opção para colocar aqui

Pesquisadora: E o que está acontecendo?

Katherine: Eu tô achando que ele tá fazendo vezes o resultado dentro desse bloquinho. Mas eu não encontrei outra opção para colocar ali.

Mesmo identificando o problema Katherine não sabe como solucioná-lo, já que de acordo com suas coordenações anteriores esse conjunto de operações todas juntas serão operadas seguindo os critérios de prioridades matemáticas de resolução: primeiro será calculada a multiplicação e depois a soma. A participante não percebe que a inclusão do bloco da soma dentro do segundo fator da multiplicação indica que ela será realizada primeiro. Esse mesmo fato ocorre com Dorothy.

O bug nos programas das participantes também está relacionado a pouca experiência com o software, pois a montagem está baseada em suas abstrações anteriores da escrita à mão em que simplesmente seria necessário escrever: resposta $\times 9+72$.

Katherine e Dorothy demonstravam em suas falas qual a ordem de resolução das operações, porém não identificam como isso deveria estar organizado no software, ou seja, seria necessário primeiramente pegar o bloco da adição e incluir em uma das parcelas o resultado da multiplicação da resposta por 9 conforme ilustra a expressão: $($ resposta $\times 9)+72$.

Desta forma, ao escrever um programa e encaixar os blocos é necessário considerar a ordem de resolução no encaixe os blocos, pois é ela que indica, no caso do Scratch, como as operações devem ser realizadas. Neste sentido, o software está proporcionando às participantes pensar sobre a estrutura do problema que precisa ser indicada no código, ativando abstrações diferentes daquelas que estão envolvidas em sua resolução no papel. Destacamos que essa nova forma de pensar provocada pelo software também precisa passar por um processo de abstrações apoiadas sobre o programa e sua forma de execução em sinergia com seus esquemas já construídos que lhe permitem fazer abstrações pseudo-empíricas de todo o processo que podem lhes permitir transformá-las em abstrações refletidas. 
Após sucessivas explorações Katherine e Dorothy observam que a posição dos blocos precisava ser alterada e demonstram essa compreensão em suas falas:

Dorothy: a questão é que ele faz o grupo né, ele vai fazer primeiro aqui o que tá dentro desse círculo e aí depois que ele vai chamar o que tá fora. (Altera a ordem dos blocos)

Katherine: Eu tenho que fazer a resposta vezes 9 mais 72 (desencaixa a soma e a multiplicação e vai movimentando os blocos até que se encaixem corretamente).

A conclusão do programa levou Dorothy a pensar nessa atividade com os alunos e o quanto o software poderia contribuir para essa compreensão da hierarquia de resolução das operações em uma expressão, pois ela acredita que logo eles identificariam que essa resolução ocorre em blocos. Segundo a participante isso contribuiria para que eles pensassem menos na regra de resolução e mais na estrutura do problema e como ele deve ser resolvido. As conclusões de Dorothy avançam no sentido que atribuímos para a inserção desses conceitos computacionais no ensino de Matemática, permitindo abstrações reflexionantes que favorecem tomadas de consciência pelos sujeitos.

\section{CONSIDERAÇÕES FINAIS}

O Pensamento Computacional não é um termo novo, mas ganhou destaque nos últimos anos com o desenvolvimento da Ciência da Computação e sua ampliação para as diversas áreas do conhecimento. Existem vários conceitos para o termo, mas no geral todos abordam a importância da abstração nesse processo. Wing, a responsável pela expansão desse movimento, apresenta que pensar computacionalmente é essencial e que um dos elementos mais importante é o processo abstração, porém pouco se discute como esse processo contribui para a aprendizagem.

Neste artigo discutimos a importância de observar os processos de abstração para além dos aspectos operacionais, que considera a abstração como retirada de informações essenciais do problema. Nesse sentido, analisa-se como os elementos da Ciência da Computação podem contribuir para provocar abstrações reflexionantes na formação de professores. Desta forma, consideramos que as teorias de Piaget e Papert contribuem para que possamos compreender como essa perspectiva do Pensamento Computacional pode favorecer a aprendizagem de conceitos matemáticos, ativando estruturas de pensamento e processos de tomada de consciência.

\section{REFERÊNCIAS}

AHO, A. Computation and Computational Thinking. The Computer Journal, v. 55, n. 7, p. $832-835,2012$

BECKER, F. Educação e construção do conhecimento. 2 ed., Porto Alegre: Penso, 2012. 200p.

BRENNAN, K; RESNICK, M. New frameworks for studying and assessing the development of computational thinking. In: Proceedings of the 2012 annual meeting of the American educational research association, Vancouver, Canadá, vol. 1, 25p.

BRACKMANN, C. P. Desenvolvimento do Pensamento Computacional através de atividades desplugadas na Educação Básica. Porto Alegre: PPGIE/UFRGS, 2017. 226p. Tese de Doutorado.

DENNING, P. The Profession of It Beyond Computational Thinking. Communications of the ACM, vol. 52, n. 6, p.28-30, jun 2009.

DENNING, P. Remaining Trouble Spots with Computational Thinking. Communications of the ACM, vol. 60, n. 3, p.33-39, mar 2017. 
diSessa, A. A. (2018). Computational literacy and "the big picture" concerning computers in mathematics education. Mathematical Thinking and Learning, v.20, n.1, p. 3-31, 2018.

GROVER, P; PEA, R. Computational Thinking in K-12: A Review of the State of the Field. In: Educational Researcher, v. 42, n.1, p. 38-43, 2013

HU, C. Computational Thinking - What It Might Mean and What We Might Do About It. In: Proceedings of the 16th annual joint conference on Innovation and technology in computer science education, ITiCSE'11, 2011, New York: ACM. p. 223-227. LI, Y., SCHOENFELD,A. H., DISESSA, A. A., GRAESSER, A. C., BENSON, L. C., ENGLISH, L. D. e DUSCHL, R. A. Computational Thinking is more about thinking than computing. Journal for STEM Education Reserach, v. 3, n. 1, p. 1-18, 2020.

PAPERT, S. Logo: computadores e educação. Tradução: José Armando Valente. São Paulo: Brasiliense, 1985. 253 p.

PAPERT, S. An Exploration in the Space of Mathematics Educations. International Journal of Computers for Mathematical Learning, v. 1, n. 1, p. 95-123, 1996

PIAGET, J. Abstração reflexionante: Relações lógico-aritméticas e ordem das relações espaciais. Porto Alegre: Artes Médicas, [1977] 1995. 292 p.

ROCHA, K. C.; BASSO, M. V. A.; NOTARE, M. R. Aproximações teóricas entre Pensamento Computacional e Abstração Reflexionante. Revista Novas Tecnologias na Educação - RENOTE, v. 18, n. 2, p. 581-590, dez. 2020

SHUTE, V. J.; SUN, C.; ASBELL-CLARKE, J. Demystifying computational thinking. Educational Research Review, v. 22, p. 142-158, nov. 2017

STEWART, I. Incríveis passatempos matemáticos. Tradução: Diego Alfaro. Rio de Janeiro: Zahar, 2010. 353 p.

WING, J. M. Computational Thinking. Communications of the ACM, v. 49, n. 3, p.3335, mar 2006.

WING, J. M. Computational Thinking Benefits Society. Social Issues In Computing, New York, 10 jan. 2014. Disponível em: http://socialissues.cs.toronto.edu/ 2014/01/computational-thinking/. Acesso em: 2 out. 2021.

YASAR, O. A New Perspective on Computational Thinking. Communications of the ACM, v. 61, n. 7, p.33-39, jul 2018. 